\title{
Comunicación pedagógica y creatividad
}

\section{Emilio Ortiz}

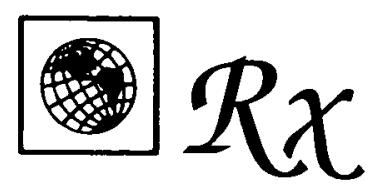

El papel de la creatividad en el proceso educativo ba sido uno de los grandes temas olvidados tanto en la investigación como en los diseños curriculares de corte tecnocrático. En este breve artículo, el autor revisa los puntos fundamentales en los que basar la acción pedagógica escolar.

A la comunicación pedagógica se le viene dedicando un espacio cada vez mayor en la literatura científica contemporánea (P. Freire, 1985; T. Konnikova, 1985; G. Valdés, 1986; J. Ibañez, 1987; R. Medina y N. Rodríguez, 1987; E. Rodríguez, 1989; M. Charles, 1991; A. Galindo, 1991; J. Mélich, 1991). A partir del creciente predominio del enfoque comunicativo en el proceso docente-educativo (E. Ortiz, 1994a).

La comunicación pedagógica constituye una variante peculiar de la comunicación interpersonal, con gran efecto instructivo y educativo no sólo en la escuela, sino en todas las esferas de la sociedad, aunque es en la escuela donde adquiere mayores potencialidades formativas por las propias funciones que cumple esta institución dentro de la sociedad.

Por su parte, las cuestiones referentes a la creatividad también son objeto de estudio sistemático (F. González y A. Mitjans, 1989; M. Martínez, 1990; A. González, 1990; F. Chivás, 1992; I. Daudinot y colaboradores, 1994). La creatividad es el proceso de descubrimiento o producción de algo nuevo que cumple exigencias de una determinada situación social (F. González y A. Mitjans, 1989).

Es poco frecuente encontrar análisis exhaustivos acerca de la relación entre comunicación y creatividad, pues aunque son fenómenos perfectamente diferenciables, se encuentran fuertemente implicados en el desarrollo de la personalidad. En el presente trabajo se exponen algunos argumentos teóricos y prácticos sobre la estrecha unidad de ambos en la labor pedagógica.

En investigaciones realizadas sobre la creatividad en la escuela (M. Martínez, 1990 e I. Daudinot y colaboradores, 1994) y en la industria (A. González, 1990), se ha demostrado fehacientemente que el incremento de la comunicación interpersonal y su eficiencia constituyen requisitos indispensables para el logro de la creatividad entre los sujetos participantes. Asimismo, en indagaciones hechas en el campo del perfeccionamiento de la comunicación pedagógica (E. Ortiz, 1994b), se confirmó que la intensificación y el perfeccionamiento del proceso comunicativo entre los 
maestros, estimulaba la creatividad en sus relaciones y en su labor pedagógica profesional.

Si bien estas evidencias favorecen la comprensión unitaria sobre ambos procesos, es necesario explicitar más estos vínculos con el fin de organizar mejor las consideraciones conceptuales y poder lograr su aplicación científica en el campo educativo. $A$ continuación se esbozan algunos criterios al respecto:

- Tanto la comunicación interpersonal como la creatividad son procesos de la personalidad, al estar conformados por etapas o fases, por transcurrir en el tiempo y presuponen un devenir espacio-temporal de carácter mediato con determinadas regularidades.

- En ambos están fuertemente implicados los fenómenos afectivos, motivacionales, cognoscitivos y conductuales de la personalidad. O sea, en ellos se refleja diáfanamente el principio de la unidad de lo afectivo y lo cognitivo que abarca a la personalidad total (F. González y A. Mitjans, 1989).

- El desarrollo intenso de uno presupone y provoca la aparición del otro, es imposible tratar de concebirlos en desarrollos paralelos. Entre los principios generales que propone B. Lomov $(1983,1989)$ está que la comunicación no se restringe a la transmisión de información, no sólo se transmite sino se crea dentro del propio proceso comunicativo. Es decir, que la evolución de la personalidad lleva implícita una comunicación creadora y una creatividad comunicativa.

- El complejo proceso creativo de la personalidad contiene, desde su inicio, no sólo a la comunicación interpsíquica (relacional), sino a la comunicación intrapsíquica (consigo mismo), ya que coexisten ambas en la persona (F. González, 1990). En esta comunicación sui generis el individuo se dicotomiza internamente dentro de sí. Predomina el lenguaje interno, por lo que prima el sentido sobre el significado, o sea, el contenido, «el problema» a solucionar adquiere valor semántico subjetivo. La comunicación intrapsíquica se produce entonces de forma constante e intensiva desde las primeras etapas creativas del hombre, adoptando disímiles variantes que van desde el diálogo hasta el soliloquio. En algunas personas adopta formas tan fuertes que se erigen en elementos reguladores de la personalidad, lo cual está asociado a un desarrollo significativo del criticismo de la personalidad.

El intenso proceso comunicativo interno es un paso previo y obligado del acto creador y, de acuerdo con las cualidades individuales, recibe matices únicos. La comunicación intrapsíquica constituye un fenómeno poco investigado aun por las dificultades evidentes para su abordaje científico, aunque hay autores que valoran este fenómeno indirectamente dentro del acto creador de científicos y artistas (S. L. Rubinstein, 1977).

- Cuando se arraigan en la personalidad, se convierten en elementos definitorios de ella que contribuyen a caracterizarlo en términos de comunicabilidad y creatividad. Una personalidad creativa es comunicativa y viceversa, una persona comunicativa es creadora, entendiendo esta comunicabilidad no en sentido intuitivo, como mera extroversión, sino en su complemento con la introversión, con una rica y plena vida interior.

Para el proceso educativo estas consideraciones tienen una salida práctica inmediata, pues el acto pedagógico es a la vez comunicativo y creador:

1. Sólo se puede estimular la creatividad en los educandos si el maestro lo es, por tanto, los contenidos referidos a la comunicación pedagógica y a la creatividad deben formar parte del plan de estudios en la carrera magisterial, desde lo académico, lo laboral y lo investigativo en la unidad de lo instructivo y lo educativo. De modo que se estimule el desarrollo de estilos comunicativos flexibles en los maestros (E. Ortiz, 1994c). 
2. El proceso de enseñanza-aprendizaje deberá estructurarse sobre la base de la búsqueda de la eficiencia comunicativa del maestro con los alumnos (E. Ortiz, 1994a) y entre los alumnos, de manera que se intensifiquen los procesos comunicativos en el aula.

3. Los problemas que se utilicen para estimular la creatividad de los alumnos a través de la búsqueda de posibles soluciones (hipótesis), deben salir de la vida práctica y cotidiana, de la historia de la sociedad y la naturaleza, y que los motiven realmente, incentivarlos a la comunicación intrapsíquica, dejarlos pensando fuera de la clase las interrogantes y contradicciones fundamentales de dichos problemas. Algunos autores como T. D'Zúrilla (1993) reafirman la relación directa entre resolución de conflictos y creatividad.

4. Despojar a las actividades docentes, extradocentes y extraescolares de todo lastre de esquematismo y rutina porque de lo contrario se convierten en barreras de la comunicación y de la creatividad. La innnovación constante y la búsqueda de lo original en la clase será una condición imprescindible sin estimular la improvisación.

5. Todos los cambios que se introduzcan deben obedecer a una estrategia previamente analizada y discutida por los maestros, aunque posean un carácter experimental.

6. La lógica de la asignatura en la búsqueda de los problemas deberá siempre corresponderse en mayor o menor medida con la lógica de la ciencia en cuestión, de acuerdo con el nivel de enseñanza con que se trabaje.

7. El maestro deberá apropiarse de una serie de conocimientos que le permita poseer una cultura general para poder impartir creadoramente los contenidos, de lo contrario, no estaría en condiciones de hacerlo eficazmente.

8. Las relaciones didácticas objetivo-contenido-método-sistema de evaluación serán sometidos a reformulaciones totales. Si al menos uno de ellos se mantiene inalterable, se comprometen los resultados.

9. Los cambios deberán irse sucediendo sistemáticamente de los temas a la asignatura y al resto de ellas para que las influencias sean cada vez más homogéneas en la búsqueda de las creatividad y la comunicación pedagógica. De lo contrario los esfuerzos quedan como intentos aislados.

10. Es evidente la complejidad didáctica y el tiempo que se le tiene que dedicar a los cambios imprescindibles. Constituyen realmente una complicación la búsqueda de los caminos no tradicionales en aras de la creatividad, sólo la llevarán hasta el final con éxito aquellos con dignidad profesional, plenamente convencidos de su utilidad educativa para el futuro de sus alumnos.

\section{Referencias}

Charles, M. (1991). Comunicación y procesos educativos. Revista Tecnológica y Comunicación Educativas 17, Mayo, 17-23.

ChIVÁs, F. (1992). Creatividad + dinámica de grupos = jeureka! La Habana: Editorial Pueblo y Educación.

DAUDINOT, I., y COLABORADORES (1994). Estimulación de la inteligencia y la creatividad en el proceso de enseñanza de biología. Inédita.

D' ZURILLA; T. (1993). Terapia de resolución de conflictos. Bilbao: Descleé de Brower.

FrEIRE, P. (1985). Dialogicidad y diálogo, p. 39-47. En Diálogo e interacción en el proceso pedagógico. México D.F.: Ediciones el Caballito.

GALINDO, A. (1991). Transmisión verbal y comunicación: bases para una evaluación positiva de los errores del aprendizaje. Revista Educar, 18, 123-132.

González, A. (1990). Cómo propiciar la creatividad. La Habana: Editorial Ciencias Sociales. 
GonZÁlez, F., y MitJANS, A. (1989). La personalidad. Su educación y desarrollo. La Habana: Editorial Pueblo y Educación.

GONZÁLEZ, F. (1990). Psicoterapia y personalidad; algunas reflexiones. Revista Cubana de Psicología. 2, VIII, 117-127.

IвÁÑEZ, J. (1987). Planteamiento filosófico-educativo del problema de la comunicación. Revista Española de Pedagogia, Julio-Septiembre, 295-304.

Konnikova, T. (1985). Metodología de la labor educativa. La Habana: Editorial Pueblo y Educación.

Lomov, B. (1983). Comunicación y regulación social de la conducta del individuo, p. 3-32. En Aspectos socio-psicológicos de la comunicación. La Habana: Facultad de Psicología. Universidad de la Habana.

LOMOV, B. (1989). El problema de la comunicación en psicología. La Habana: Editorial Ciencias Sociales.

MARTínez, M. (1990). La creatividad en la escuela. La Habana: Evento Internacional Pedagogía'90.

MEDINA, R. y RoDríguez, N. (1987). Comunicación interpersonal y educación. Revista Española de Pedagogia, Julio-Septiembre, 305-320.

MÉLICH, J. (1991). Instrucción, educación y encuentro comunicativo en el aula. Revista Educar, 18, 5362.

ORTIz, E. (1994a). El enfoque comunicativo del proceso pedagógico. Inédito.

ORTIz, E. (1994b). El perfeccionamiento del estilo comunicativo del maestro para su labor pedagógica. Tesis de doctorado. Inédita.

ORTIZ, E. (1994c). El estilo comunicativo del maestro. Inédito.

RODRfGUEZ, E. (1989). Comunicación pedagógica. Revista Tecnológica y Comunicación Educativas 4, Octubre, 9-15.

RuBINSTEjn, S.L. (1977). Principios de psicología general. La Habana: Edición Revolucionaria.

VALDEs, G. (1986). Espacio educativo y comunicación. Revista Tecnológica y Comunicación Educativas 4, Agosto-Octubre, 23-28.

VYGOTSKI, L. S. (1979). El desarrollo de los procesos psíquicos superiores. Barcelona: Crítica.

\section{Comunicación pedagógica y creatividad Emilio Ortiz Torres$$
\text { CL\&E, 1995, 28, pp. 73-76 }
$$

Resumen: Se revisan en este artículo los presupuestos sobre los que basar el tratamiento pedagógico de la creatividad y se proponen algunos principios didácticos desde su enfoque históricocultural.

Dirección: Facultad de Ciencias Sociales. Instituto Superior Pedagógico «José de la Luz y Caballero». Avda. de los Libertadores, km 3,5. 80100 Holguín (Cuba).

C.PERMISOS PARA CITAR O REPRODUCIR EN OTRAS FUENTES: Se pueden citar libremente hasta 500 palabras. Para reproducir una porción de texto mayor, figuras o ilustraciones, se deberá pedir permiso por escrito a la revista, especificando el uso al que se destina el texto. En todos los casos, se deberá citar el copyright de $C L \& E$. En el caso de artículos o textos que hayan sido a su vez reproducidos en $C L \& E$ los interesados deberán dirigirse tanto a los detentadores del copyright original como a $C L \& E$, en el caso de que se quiera hacer uso de la traducción. FOTOCOPIAS: Para todo lo relacionado con el uso mediante fotocopia del material de esta revista, deberán dirigirse a: CEDRO, $\mathrm{C} /$ José Marañón, 10,3. Izda. Tel. 5941575 . Fax 4453567 